Article

\title{
High Polymorphism in the Dmrt $2 a$ Gene Is Incompletely Sex-Linked in Spotted Scat, Scatophagus argus
}

\author{
Umar Farouk Mustapha (D), Daniel Assan, Yuan-Qing Huang, Guang-Li Li $\mathbb{D}^{(D)}$ and Dong-Neng Jiang *(D)
}

check for updates

Citation: Mustapha, U.F.; Assan, D. Huang, Y.-Q.; Li, G.-L.; Jiang, D.-N. High Polymorphism in the Dmrt2a Gene Is Incompletely Sex-Linked in Spotted Scat, Scatophagus argus. Animals 2022, 12, 613. https:// doi.org/10.3390/ani12050613

Academic Editor:

Jean-Marie Exbrayat

Received: 18 January 2022

Accepted: 25 February 2022

Published: 28 February 2022

Publisher's Note: MDPI stays neutral with regard to jurisdictional claims in published maps and institutional affiliations.

Copyright: (C) 2022 by the authors. Licensee MDPI, Basel, Switzerland. This article is an open access article distributed under the terms and conditions of the Creative Commons Attribution (CC BY) license (https:// creativecommons.org/licenses/by/ $4.0 /)$.

\begin{abstract}
Fisheries College of Guangdong Ocean University, Guangdong Provincial Key Laboratory of Pathogenic Biology and Epidemiology for Aquatic Economic Animals, Guangdong Province Famous Fish Reproduction and Breeding Engineering Technology Research Center, Zhanjiang 524088, China; umarfk.gh@gmail.com (U.F.M.); cobbykarsh508@gmail.com (D.A.); huangyuanqing2@stu.gdou.edu.cn (Y.-Q.H.); guangligdou@163.com (G.-L.L.) * Correspondence: dnjiang@gdou.edu.cn
\end{abstract}

Simple Summary: Fishes have relatively younger chromosomes than mammals and birds, making them excellent models to study sex chromosome differentiation in teleosts. The spotted scat has a young chromosome, making it an ideal model to study the evolution of sex chromosomes in vertebrates. The doublesex and Mab-3-related transcription factor 1 (Dmrt1) is the candidate sex determination gene in spotted scat, while the differentiation of other sex-linked genes remains unknown. Dmrt2a is positioned close to Dmrt3 and farther away from Dmrt1 on the same chromosome, while Dmrt $2 b$ is not. Dmrt2a is highly expressed in testicular tissues, with several intronic and exonic mutations that do not affect gene translation. Using intronic markers, we found in 4 different populations that Dmrt2a is incompletely sex-linked. Incomplete sex linkage of markers suggests the absence of recombination depression in this region and indicates that the system of sex chromosomes is still young. This suggests that Dmrt2a might be necessary for developmental processes. Other possibilities are that the conservation differences between Dmrt1, Dmrt3, and Dmrt2a might be due to gene dosage effect, or specialization of truncated copies of Dmrt1 and Dmrt3 in the regulation of normal gene copies. The partial sex linkage of Dmrt2a suggests an excellent model for studying sex-linked gene differentiation during vertebrate evolution. Therefore, further studies are needed to identify the regulators of Dmrt2a expression, sequences of $\mathrm{X}$ and $\mathrm{Y}$ copies, and their functions in spotted scat.

\begin{abstract}
Unlike mammals and birds, many fishes have young sex chromosomes, providing excellent models to study sex chromosome differentiation at early stages. Previous studies showed that spotted scat possesses an XX-XY sex determination system. The X has a complete Dmrt3 copy (termed normal) and a truncated copy of Dmrt1 (called Dmrt1b), while the $Y$ has the opposite (normal Dmrt1, which is male-specific, and a truncated Dmrt3 called Dmrt3 $\triangle-Y$ ). Dmrt1 is the candidate sex determination gene, while the differentiation of other sex-linked genes remains unknown. The spotted scat has proven to be a good model to study the evolution of sex chromosomes in vertebrates. Herein, we sequenced a neighbor gene of this family, Dmrt2, positioned farther from Dmrt1 and closer to Dmrt3 in the spotted scat, and analyzed its sequence variation and expression profiles. The physical locations of the three genes span across an estimated size of $>40 \mathrm{~kb}$. The open reading frames of Dmrt $2 a$ and its paralog Dmrt $2 b$ are $1578 \mathrm{bp}$ and $1311 \mathrm{bp}$, encoding peptides of 525 and 436 amino acid residues, respectively. Dmrt2a is positioned close to Dmrt3 but farther from Dmrt1 on the same chromosome, while Dmrt $2 b$ is not. Sequence analysis revealed several mutations; insertions, and deletions (indels) on Dmrt2a non-coding regions and single-nucleotide polymorphisms (SNPs) on the Dmrt2a transcript. These indels and SNPs are sex-linked and showed high male heterogeneity but do not affect gene translation. The markers designed to span the mutation sites tested on four different populations showed varied concordance with the genetic sexes. Dmrt $2 a$ is transcribed solely in the gonads and gills, while Dmrt2b exists in the gonads, hypothalamus, gills, heart, and spleen. The Dmrt2a and $D m r t 2 b$ transcripts are profoundly expressed in the male gonads. Analyses of the transcriptome data from five other fish species (Hainan medaka (Oryzias curvinotus), silver sillago (Sillago sihama), Nile tilapia (Oreochromis niloticus), Hong Kong catfish (Clarias fuscus), and spot-fin porcupine fish (Diodon
\end{abstract}


hystrix)) revealed testes-biased expression of Dmrt1 in all, similar to spotted scat. Additionally, the expression of Dmrt2a is higher in the testes than the ovaries in spotted scat and Hainan medaka. The Dmrt2a transcript was not altered in the coding regions as found in Dmrt1 and Dmrt3 in spotted scat. This could be due to the functional importance of Dmrt2a in development. Another possibility is that because Dmrt $2 a$ is positioned farther from Dmrt1 and the chromosome is still young, meaning it is only a matter of time before it differentiates. This study undeniably will aid in understanding the functional divergence of the sex-linked genes in fish.

Keywords: Dmrt2a; mutations; indels; SNPs; sex-linked; sex-chromosome; gene expression; Scatphagus argus

\section{Introduction}

The evolution of sex determination (SD) genes, sex chromosomes, and SD systems have attracted the interest of biologists for decades. The sex determination systems of most mammals and birds are XX-XY and ZZ-ZW, and the $\mathrm{Y} / \mathrm{W}$ chromosome is degraded in varying degrees [1]. Over 30,000 known fish species have genetic sex determination, environmental sex determination, and combined environmental and genetic sex determination systems [2]. The genetic sex determination of fishes includes XX-XY, ZZ-ZW, and multiple sex chromosomes. Most fish sex chromosomes are poorly differentiated, making it challenging to identify sex chromosomes and sex-determining genes. On the other hand, with the assistance of modern molecular and sequencing technologies, many SD and candidate SD genes have been cloned. In 2002, the first fish sex-determining gene, the DW domain gene on the $\mathrm{Y}$ chromosome (dmy), a duplicated copy of $d m r t 1$ in the sex-determining region of the $\mathrm{Y}$ chromosome $(d m r t 1 b Y)$, was cloned in Japanese medaka (Oryzias latipes). Sex-determining and candidate genes were cloned in only around ten fish species [3-6]. The origins of new sex determination genes fall into two categories, including allelic diversification and gene duplication followed by neo- or sub-functionalization [7]. Sex chromosome is originated from the autosome. Firstly, a novel sex-determining gene is evolved on the autosome. Some sexually antagonistic alleles (genes beneficial to one sex but harmful to the other) evolve near the sex-determining gene. The number of sex antagonistic genes continues to increase, and the region of sex determination accumulates repetitive sequences. The recombination of sex chromosomes inhibits the formation of a sex-linked differentiation region, and the sex chromosomes gradually differentiate [8]. Most fish lack differentiated sex chromosomes, and the sexes of many fish species are controlled by genetic factors on the young sex chromosomes, making fishes good models for studying the early formation of sex-determining genes and sex chromosomes in vertebrates. The presence of sex-determining genes that should not recombine and the evolution of Y-linked genes that benefit only male functions can lead to recombination suppression between sex chromosomes. Recombination between genes is affected by evolution, with genes in which recombination stopped before the splitting of taxa being less diverged than those after [9], indicating a relationship between age and recombination between genes.

The doublesex and mab-3-related transcription (Dmrt) member genes are intensely conserved regulators in the sexual development of metazoan [10]. The Dmrt genes have been reported in more than 30 fish species, most of which are related to sexual development [11]. The Dmrt member genes widely encode proteins with highly conserved DM domain and exist differently in both vertebrates and invertebrates, suggesting the possibility of additional functions besides sexual development [12-16]. The genes encompass major transcription factors involved in neurogenesis, sex determination and differentiation pathways, organ development, growth and maintenance, and somite differentiation [17-19]. In humans, 8 Dmrt member genes exist, along with 7 in mice, 11 in C. elegans, 4 in Drosophila, and 6 in fish (Dmrt1-6) [3,11-15,20-25]. The fish Dmrt1-Dmrt5 genes were relatively conserved while Dmrt6 was lost in most species during the evolution- 
ary process [11]. However, in mice, multiples of Dmrts have been reported to participate in sexual development [21]. Similarly, duplicates of Dmrt1, -2 , and -3 have been identified in most fish species [3,12,13,26,27].

Dmrt2 is an important Dmrt member gene but is controversial due to its participation in gonad development and other non-gonadal functions $[19,28]$. The Dmrt2 is essential for somite development and left-right patterning, and is expressed in the dermomyotome of developing vertebrate somites $[29,30]$. In situ hybridization revealed that Dmrt2a is expressed in germ cells of the developing swamp eel [31]. In Megalobrama amblycephala, Dmrt2a and Dmrt $2 b$ essentially showed similar expression levels between testis and ovary samples [13]. However, in species such as Medaka, Oryzias latipes [22], zebrafish, Danio rerio [26], swamp eel, Monopterus albus [31], and blunt snout bream Megalobrama amblycephala [13], Dmrt2/Dmrt2a was more predominantly expressed in the testicular tissues than in the ovaries.

Spotted scat is an important marine culturable fish distributed in Southern and Eastern Asia. Its moderate body size and flat shape make it a good experimental fish. Sequence analysis and the development of sex-linked markers indicate that Dmrt1 is tightly linked to male sex in spotted scat [3]. Additionally, genome sequencing revealed that Dmrt1 only existed in XY male fish, while the mutated copy of Dmrt1 (Dmrt1b) is located on the X chromosome [32,33]. The male-specific Dmrt1 is the candidate SD gene in spotted scat [3]. The Dmrt3 $\triangle-Y$ is a truncated mutation of Dmrt3, and it's also Y-linked in spotted scat. On the other hand, the situation for Dmrt2a is not known in spotted scat. In this study, we sought to determine whether the Dmrt2a is sex-linked, and if so, whether sex linkage is complete and whether the $\mathrm{Y}$ - and $\mathrm{X}$-linked copies differ in sequence or expression. Herein, we isolated Dmrt2a and Dmrt $2 b$ from spotted scat. The genomic organization revealed a size variation of insertions and deletions (indels) of Dmrt2a. The indels are sex-linked at different rates across populations, while the expression of Dmrt2a in the gonads of spotted scat is in line with previous reports.

\section{Materials and Methods}

\subsection{Animals and Sample Collection}

Initially, adults Scatophagus argus was purchased from Dongfeng Market (Zhangjiang, Guangdong, China) and transported to the laboratory with adequate oxygen. Fish weights and measurements were taken and sacrificed by decapitation after $100 \mathrm{mg} / \mathrm{L}$ of tricaine methanesulfonate (MS 222, Sigma, Saint Louis, MO, USA) anesthetization. The average lengths and weights of the adult spotted scat used in this study were $18.5 \mathrm{~cm}$ and $169.9 \mathrm{~g}$ for male and $19.2 \mathrm{~cm}$ and $204.5 \mathrm{~g}$ for female, respectively. Male and female tissues, including hypothalamus, pituitary, gonad, gill, heart, kidney, liver, spleen, stomach, intestine, and muscle tissues, were carefully excised and snap-frozen in liquid nitrogen, then stored at $-80^{\circ} \mathrm{C}$ before RNA isolation. Tail fins were also taken for DNA extraction. Parts of the gonadal samples were kept in Bouin's solution for further histological studies (hematoxylin and eosin staining). For further analysis, we sampled fish from four different populations, from Donghai Dao, Beihai, Xiashan, and Zhuhai. The population from Donghai Dao was artificially bred from mixed parents, while the population from Zhuhai was bred from two parents and twenty-four progenies. The populations from Beihai and Xiashan were obtained from the wild with unknown genetic background. All experimental fish protocols followed the guidelines and approval of the Administration of Affairs Concerning Experimental Animals for the Science and Technology Bureau of China, and the Animal Research and Ethics Committees of Guangdong Ocean University.

\subsection{RNA Isolation and cDNA Synthesis}

Total RNA was prepared using TRIzol reagent (Invitrogen), according to the manufacturer's instructions. The RNA integrity was assessed on $1 \%$ agarose gel electrophorese and visualized by ethidium bromide. Approximately $1 \mu \mathrm{g}$ of total RNA from each sample 
was used for the first-strand cDNA synthesis using the PrimeScript ${ }^{\mathrm{TM}} \mathrm{RT}$ reagent kit with gDNA Eraser (Takara, China), according to the manufacturer's instruction.

\subsection{Genotypic and Phenotypic Sex Identification}

Nucleic acid purification kit (N1173, Dongsheng Biotecon, Guangzhou, China) was used for the DNA extraction following the manufacturer's instruction. Sex-specific DNA Marker (Dmrt1-Marker-F/R) (forward primers: 5' - GAAGGCAGCA AGATCAGGAGGA$3^{\prime}$ and reverse primers: $5^{\prime}$ - CAGCAGCAGGTCAGATGGTTCC-3') as described in $[3,34]$ was used to determine the genetic sex of the spotted scat. Hematoxylin and eosin staining (H\&E) of spotted scat gonads was also employed to confirm the genotypic sex and gonad developmental stage determination described in our previous studies [3,34]. The Dmrt1Marker-F/R used for the genetic sex identification was previously found to be $100 \%$ accurate when tested on 113 males and 133 females from five different populations (both wild and hatchery) in China [3]. The current study also observed a $100 \%$ concordance rate of the Dmrt1-Marker-F/R with the phenotypic sex as determined by H\&E staining.

\subsection{Cloning of Dmrt2a and Dmrt2b in S. argus}

The complete cDNA sequences of $S$. argus Dmrt2a and Dmrt $2 b$ were obtained from our mixed tissues [35] and gonad [36] transcriptome data. Nile tilapia Dmrt2a (NCBI accession number: NP_001266696) and Dmrt2b (NCBI accession number: AAX08123) mRNA sequences were used as query sequences to blast our transcriptome sequence data.

Primers flanking the open reading frame (ORF) were designed with reference to the transcript obtained, and the full lengths of $S$. argus Dmrt2a and Dmrt $2 b$ were cloned as described in [3]. The PCR protocol used was as follows: initial denaturation at $94{ }^{\circ} \mathrm{C}$ for $3 \mathrm{~min}, 37 \mathrm{cycles}$ of denaturation at $94{ }^{\circ} \mathrm{C}$ for $30 \mathrm{~s}$, annealing at $60^{\circ} \mathrm{C}$ for $30 \mathrm{~s}$ and extension at $72{ }^{\circ} \mathrm{C}$ for $2 \mathrm{~min}$, followed by a final extension of $10 \mathrm{~min}$ at $72{ }^{\circ} \mathrm{C}$. The PCR products were then examined on $2 \%$ agarose gel stained with ethidium bromide. Amplification bands were extracted from the gel, purified, and cloned into the p-Easy-T3 vector (TransGen Biotech, Beijing, China) as described previously [34]. All primers used and the GenBank accession numbers of Dmrt genes are listed in Tables S1 and S2, respectively.

\subsection{Sequence Analysis and Bioinformatics}

The cDNA sequences of Dmrt2a and Dmrt2b were spliced and analyzed by DNASTAR software (http:/ / www.dnastar.com/, accessed on 2 October 2021). ORFs and protein sequences were predicted using the NCBI ORFfinder software (https:/ / www.ncbi.nlm. nih.gov /, accessed on 15 October 2021). Nucleotide and protein sequence homology and multiple alignments were performed using MegAlign in the DNASTAR software and ClustalX (http:/ / www.clustal.org/, accessed on 17-10-2021), respectively. The neighborjoining method was used to construct the phylogenetic tree in MEGA 6.06 (http: / www. megasoftware.net/, accessed on 17 October 2021) with a bootstrap value of 1000 replicates. The conserved regions of the putative amino acids sequences were predicted using SMART (http:/ / smart.embl-heidelberg.de/ accessed on 17-10-2021). The protein sequences of Dmrt $2 a$ and Dmrt $2 b$ in other fish were obtained from the NCBI database and Ensembl Genome Browser (http://www.ensembl.org/Multi/Tools/Blast?db=core, accessed on 20 October 2021), and their accession numbers are listed in Table S2, including the spotted scat Dmrt2a and Dmrt $2 b$ cloned in this study.

\subsection{Designing of Markers on Dmrt2a Genomic DNA Sequence}

Based on the assembly of gDNA sequence from male and female spotted scat, markers were developed on sections of the sequence with insertions and deletions (indels). Five insertions and deletions were found, and five markers were designed. The marker with long indels (99 bp) was analyzed on agarose gel electrophoresis, while those with short indels (8 bp-14 bp) were analyzed on PAGE gel. According to the indel position, the markers spanning indel1, indel2, indel3, indel4, indel5, and del6 were named marker-1, 
marker-2, marker-3, marker-4, marker-5, and marker-6, respectively (Table 1), whereas marker-7 spanned across three SNPs (I, II, and III).

Table 1. Comparisons of marker-2 and marker-3 with genetic sex of spotted scat samples from different populations.

\begin{tabular}{|c|c|c|c|c|c|}
\hline \multirow[b]{2}{*}{ Population } & \multirow[b]{2}{*}{$\begin{array}{l}\text { Sample Size and } \\
\text { Genotype }\end{array}$} & \multicolumn{2}{|c|}{ Marker-2/Indel2-8 bp (Intron1) } & \multicolumn{2}{|c|}{ Marker-3/Indel3-12 bp (Intron3) } \\
\hline & & Consistency & $\begin{array}{c}\text { Average Concordance } \\
\text { Rate (\%) }\end{array}$ & Consistency & $\begin{array}{c}\text { Average Concordance } \\
\text { Rate }(\%)\end{array}$ \\
\hline \multirow{2}{*}{ Donghai Dao } & $19 \oplus^{8}$ & $\mathrm{a} / \mathrm{b}\left(19 \widetilde{\sigma}^{\top}\right)$ & 100 & 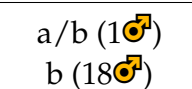 & $\begin{array}{l}5.3 \\
94.7\end{array}$ \\
\hline & 258 & $\mathrm{a} / \mathrm{b}(25 \%)$ & 100 & $\mathrm{~b}(258)$ & 100 \\
\hline \multirow{2}{*}{ Beihai } & $17 \odot^{\circ}$ & $\begin{array}{l}\mathrm{a}\left(10 \Phi^{\circledR}\right) \\
\mathrm{a} / \mathrm{b}\left(7 \Phi^{\top}\right)\end{array}$ & $\begin{array}{l}58.8 \\
41.2\end{array}$ & 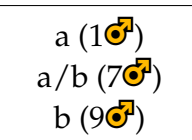 & $\begin{array}{c}5.9 \\
41.2 \\
52.9\end{array}$ \\
\hline & 138 & $\begin{array}{c}a(58) \\
\text { a/b (8\&) }\end{array}$ & $\begin{array}{l}38.5 \\
61.5\end{array}$ & b (13영) & 100 \\
\hline \multirow[b]{2}{*}{ Xiashan } & $24 \odot^{0}$ & 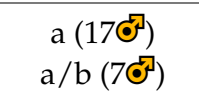 & $\begin{array}{l}70.8 \\
29.2\end{array}$ & $\begin{array}{c}\mathrm{a} / \mathrm{b}\left(18 \odot^{\circledR}\right) \\
\mathrm{b}\left(6 \odot^{\circledR}\right)\end{array}$ & $\begin{array}{l}75 \\
25\end{array}$ \\
\hline & 248 & $\begin{array}{c}\text { a (6\&) } \\
\text { a/b (11\&) } \\
\text { b (7\&) }\end{array}$ & $\begin{array}{c}25 \\
45.8 \\
29.2\end{array}$ & $\mathrm{~b}(248)$ & 100 \\
\hline \multirow[b]{2}{*}{ Zhuhai } & $15 \odot^{\circ}$ & 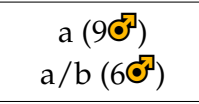 & $\begin{array}{l}60 \\
40\end{array}$ & $\begin{array}{l}\mathrm{a} / \mathrm{b}\left(13 \sigma^{\varpi}\right) \\
\mathrm{b}\left(2 \sigma^{\natural}\right)\end{array}$ & $\begin{array}{l}86.7 \\
13.3\end{array}$ \\
\hline & 198 & $\begin{array}{c}\text { a (1\&) } \\
\text { a/b (9\&) } \\
\text { b (9\&) }\end{array}$ & $\begin{array}{c}5.3 \\
47.4 \\
47.4\end{array}$ & b (198) & 100 \\
\hline \multirow{2}{*}{ TOTAL } & $75 \odot$ & 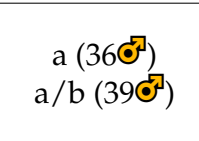 & $\begin{array}{l}48 \\
52\end{array}$ & 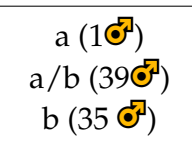 & $\begin{array}{c}1.3 \\
52 \\
46.7\end{array}$ \\
\hline & 818 & $\begin{array}{c}\text { a (12\&) } \\
\text { a/b (53\&) } \\
\text { b (16\&) }\end{array}$ & $\begin{array}{l}14.8 \\
65.4 \\
19.8\end{array}$ & $\mathrm{~b}(81 \&)$ & 100 \\
\hline
\end{tabular}

Note: For marker-2, bands "a", “a/b" indicate 147 bp and (147 and 139 bp) bands, respectively. For marker-3, bands "a" "a/b" and "b" indicate a 160 bp, (160 and 148 bp) and 148 bp bands, respectively. The "a" and "b" represent shorter and longer bands.

\subsection{Tissue Distribution}

Tissue distribution analysis was performed by reverse-transcription PCR (RT-PCR). Here, $\beta$-actin (accession number: KC161966) expression was used as an internal reference for gene normalization. The Dmrt2a,Dmrt2b, and $\beta$-actin primers for tissue distribution are listed in Table S1. The amplification regime consisted of 35 cycles ( $\beta$-actin 28 cycles) of $30 \mathrm{~s}$ at $95{ }^{\circ} \mathrm{C}, 30 \mathrm{~s}$ at $60^{\circ} \mathrm{C}$, and $30 \mathrm{~s}$ at $72{ }^{\circ} \mathrm{C}$; followed by further extension at $72{ }^{\circ} \mathrm{C}$ for $10 \mathrm{~min}$. PCR products were separated on a $2.0 \%$ agarose gel and visualized with ethidium bromide.

\subsection{Real-Time Quantitative PCR ( $q P C R$ )}

Ovaries and testes were dissected from female and male adult fish. Total RNA extraction and cDNA syntheses were carried out as described previously [37]. The relative levels abundance of Dmrt $2 a$ and Dmrt $2 b$ transcripts were evaluated using the formula $\left(\mathrm{R}=2^{-\Delta \Delta \mathrm{Ct}}\right)$. Here, $\beta$-actin was used as a reference gene to normalize the expression values. The qPCR primer sequences are listed in Table 1. Data are presented as the means \pm SD. Statistical analysis was performed using SPSS 16.0 (SPSS, Chicago, IL, USA). Significant 
differences between groups were analyzed via one-way ANOVA with Duncan's post-hoc test using a confidence level of $p<0.05$.

\subsection{Dmrt2a and Dmrt2b Expression in Transcriptome Data of Different Fish Species}

We analyzed various transcriptome data for gonadal tissues to understand the expression patterns of the Dmrt2a\&b in different species. Either zebrafish or spotted scat Dmrt1, Dmrt $2 a$, and Dmrt $2 b$ transcripts were used as query sequences to blast the transcriptome data (cds) of spotted scat [36], Hainan medaka (Oryzias curvinotus) [38], silver sillago (Sillago sihama) [39], Nile tilapia (Oreochromis niloticus) [40], Hong Kong catfish (Clarias fuscus) [41], and spot-fin porcupine fish (Diodon hystrix) [42]. For confirmation, the results with different transcript numbers and maximum hits were blasted using NCBI nucleotide blast (https:/ / blast.ncbi.nlm.nih.gov/Blast.cgi, accessed on 15 October 2021). The transcript number of confirmed genes from the cds was traced into the annotations to identify the expression in either fragment per kilobase per million mapped read (FPKM) or reads per kilobase per million mapped read (RPKM) values.

\section{Results}

\subsection{Cloning and Sequence Analysis of Spotted Scat Dmrt2a and Dmrt2b}

Previously, we showed that the spotted scat Dmrt1 is a candidate sex determination gene. In spotted scat Dmrt1 is an upstream gene of Dmrt3 $\triangle-Y$ [3], while Dmrt2a is a downstream gene of Dmrt3 $\triangle-Y$. Previously, Dmrt1 and Dmrt3 $\triangle-Y$ were found to be sexlinked, while Dmrt2a was not known, but detected to be sex-linked in this study (Figure 1). The neighbor genes of Dmrt1b and Dmrt2 on spotted scat X-chromosome are similar to other species, whiles that of spotted scat is not yet clear (Figure 1).

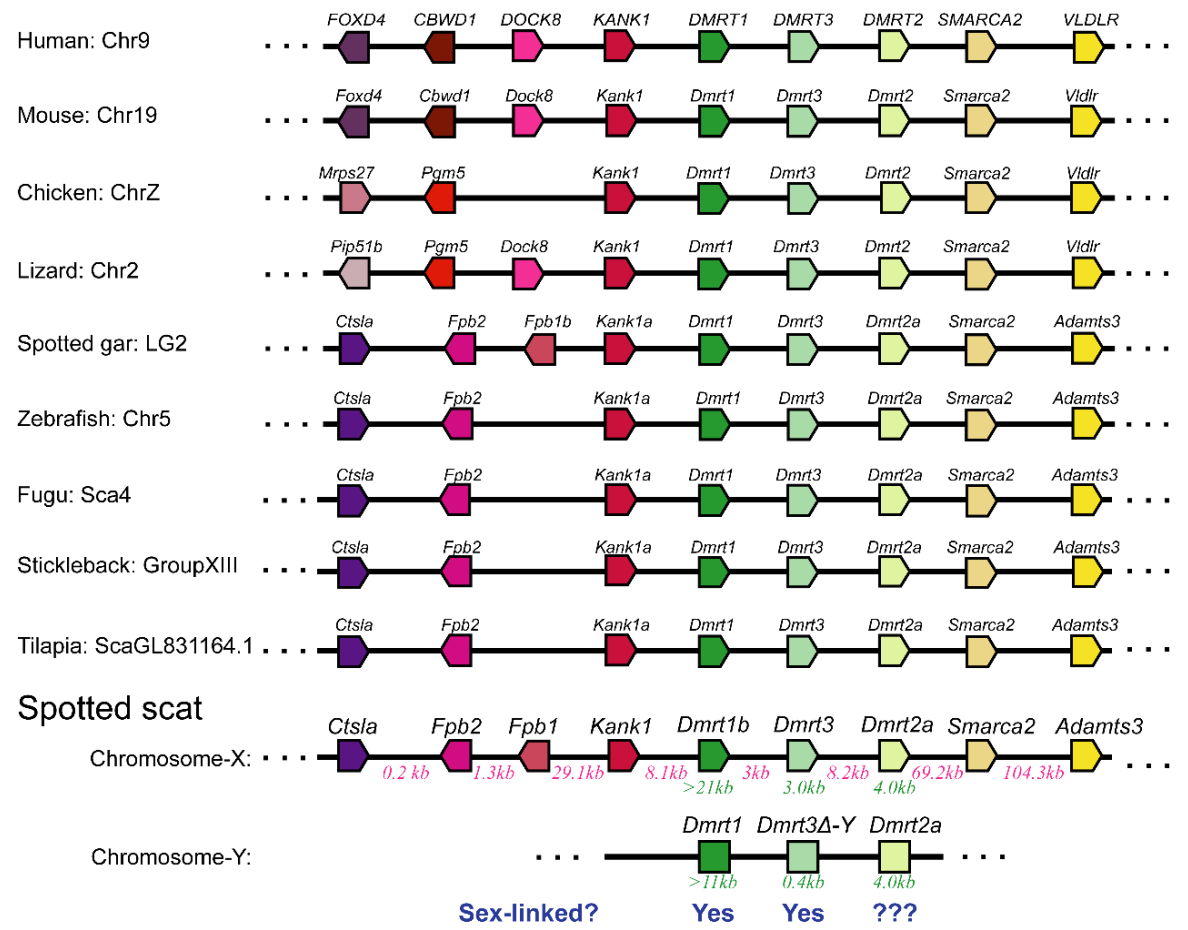

Figure 1. Syntenic analyses of Dmrt1 and Dmrt3 and their adjacent genes in different species. The figure was adopted with modifications from [3]. The bar lengths are disproportionate to the distances between genes. Dmrt1 and its downstream gene Dmrt3 $\triangle-Y$ are sex-linked in spotted scat, whiles Dmrt2a is unknown. The distance between spotted scat Dmrt genes is shown in red (in kb). The lengths of Dmrt genes are shown in green (in kb). The neighbor genes of Dmrts on the X-chromosome were obtained from our previous XX genomic data (https://ngdc.cncb.ac.cn/search/?dbId=gwh\&q= GWHAOSK00000000.1, accessed on 5 February 2022). 
The estimated length of Dmrt1 (Exons 1, 2, 3, 4, 5 and Introns 1, 2, and 3) excluding the length of intron 4 is $>11 \mathrm{~kb}$, while $D m r t 1 b$ is $>21 \mathrm{~kb}$. The distance between Dmrt1, Dmrt3 $\triangle-Y$, and Dmrt2a is unclear and will be elucidated. The estimated distance between Dmrt1b and Dmrt $2 a$ is $14.2 \mathrm{~kb}$, while Dmrt1 and Dmrt $2 a$ may also be similar. The physical location of the three genes spans across an estimated size of $40 \mathrm{~kb}$.

The lengths of spotted scat Dmrt2a and Dmrt2b genes isolated in this study were 1578 and 1311 base pairs (bp) encoding proteins of 525 and 436 amino acid (aa) residues, respectively (Figure S1A,B). Sequence alignment indicated that Dmrt2a and Dmrt2b have important DM domains, while the cysteine and histidine residues were well conserved in all species analyzed (Figure 2A and Figure S1). Additionally, located within the DM domain region of Dmrt $2 a$ and $D m r t 2 b$ is the conserved nuclear localization signal (NLS) sequence $(\mathrm{KGHKK} / \mathrm{R})$ and two intertwined zinc-binding sites (thus, sites I and II) for (Dmrt2a: C72/C75/H78/C91 and H87/C96/C98/C101) and (Dmrt2b: C69/C72/H75/C88 and H84/C93/C95/C98), respectively (Figure 2A). Little homology was observed outside the DM domain region in all species.

A
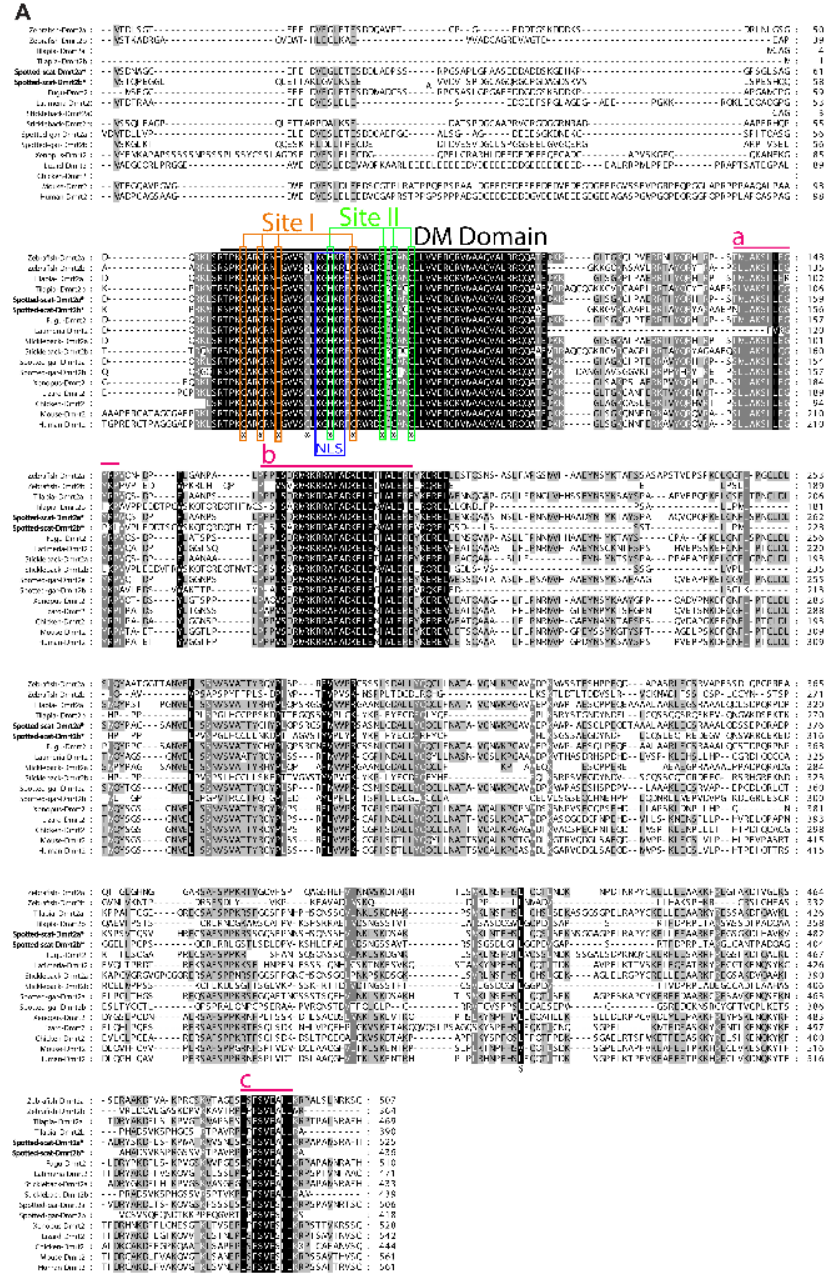

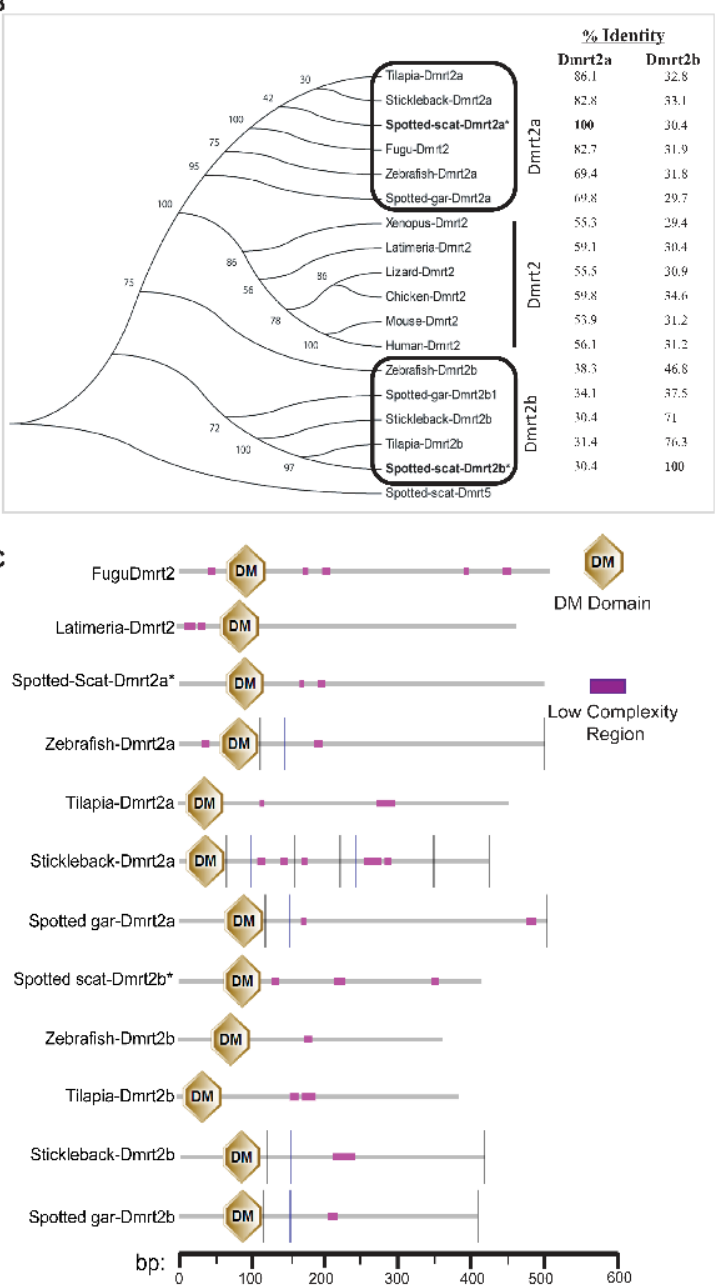

Figure 2. Homologous comparison of spotted scat Dmrt2a and Dmrt $2 b$ amino acid (aa) sequences with other species. (A) Alignment of Dmrt2a and Dmrt2b (aa) from different species. Amino acid (aa) sequences are numbered to the right. The dark overline indicates the conserved DM domain region. The two intertwined zinc-binding sites, site I (CCHC) and II (HCCC), are shown. The putative nuclear localization signal NLS is indicated. Red over lines numbered $\mathrm{a}, \mathrm{b}$, and $\mathrm{c}$ are other Dmrt 2 conserved regions. Asterisk indicates the conserved cysteine and histidine residues. (B) Phylogenetic analysis of Dmrt2 proteins from different species based on outgroup of spotted scat Dmrt5. The neighbor-joining 
method of MEGA 6 was used to develop the tree. Numbers on nodes indicate the credibility of the branches using 1000 bootstrap replicates. Asterisks indicate cloned spotted scat Dmrt2a and $D m r t 2 b$ and clustered among their counterparts. The identities of spotted scat Dmrt $2 a$ and Dmrt $2 b$ amino acid sequences with other spices are shown on the right side. (C) Schematic representation of Dmrt2 domain features of different species predicted by SMART (http:/ / smart.embl-heidelberg.de/, accessed on 17 October 2021). The scale bar indicates the length of amino acids (aa) in base pairs (bp). The hexagons indicate DM domain regions. The accession numbers of the sequences used are described in Table S2.

Based on the phylogenetic analysis, Dmrt2s analyzed were grouped into three clusters (Dmrt2a,Dmrt2, and Dmrt2b). The overall sequences of spotted scat Dmrt $2 a$ and Dmrt $2 b$ share $30.4 \%$ identity. Phylogenetically, spotted scat Dmrt2a and Dmrt $2 b$ are much closer to their counterparts in tilapia, sharing the highest percentage identity $(86.1 \%$ and $76.3 \%$, respectively). Comparatively, all teleosts Dmrt $2 a$ and Dmrt $2 b$ were clustered separately into different clades, indicating similarities and dissimilarities (Figure 2B). Additionally, SMART blast analysis predicted the spotted scat Dmrt2a and Dmrt $2 b$ to be similar to their fish counterparts (Figure 2C).

\subsection{The Dmrt2a Genomic Sequence in Female and Male Spotted Scat Is Dissimilar}

Genotypic and phenotypic sex identification of spotted scat was carried out as described in [3] before subsequent use for other analysis. The initial analysis of the genomic sequence of male and female spotted scat revealed some dissimilarities. The information regarding the genomic sequence data was previously published by our group [32]. Further gDNA cloning and sequence analysis from 3 males and 3 females revealed dispersed insertions and deletions (indels) in introns 1 and 2 (Figure 3). However, the gene structures of spotted scat Dmrt $2 a$ and Dmrt $2 b$ are comparable to other species, except that the intron 1 of $D m r t 2 a$ is more extended (2040 bp) than that of other species, with the closest being zebrafish with $1720 \mathrm{bp}$. The vast difference between the intron 1 of spotted scat and other species is probably due to the numerous indels (Figure 3). In addition, three SNPs, one on exon 2 (I) and two on intron 2 (II and III), were also found. However, the SNP I on the coding region did not change the amino acid sequence, meaning it could not result in functional mutation. 


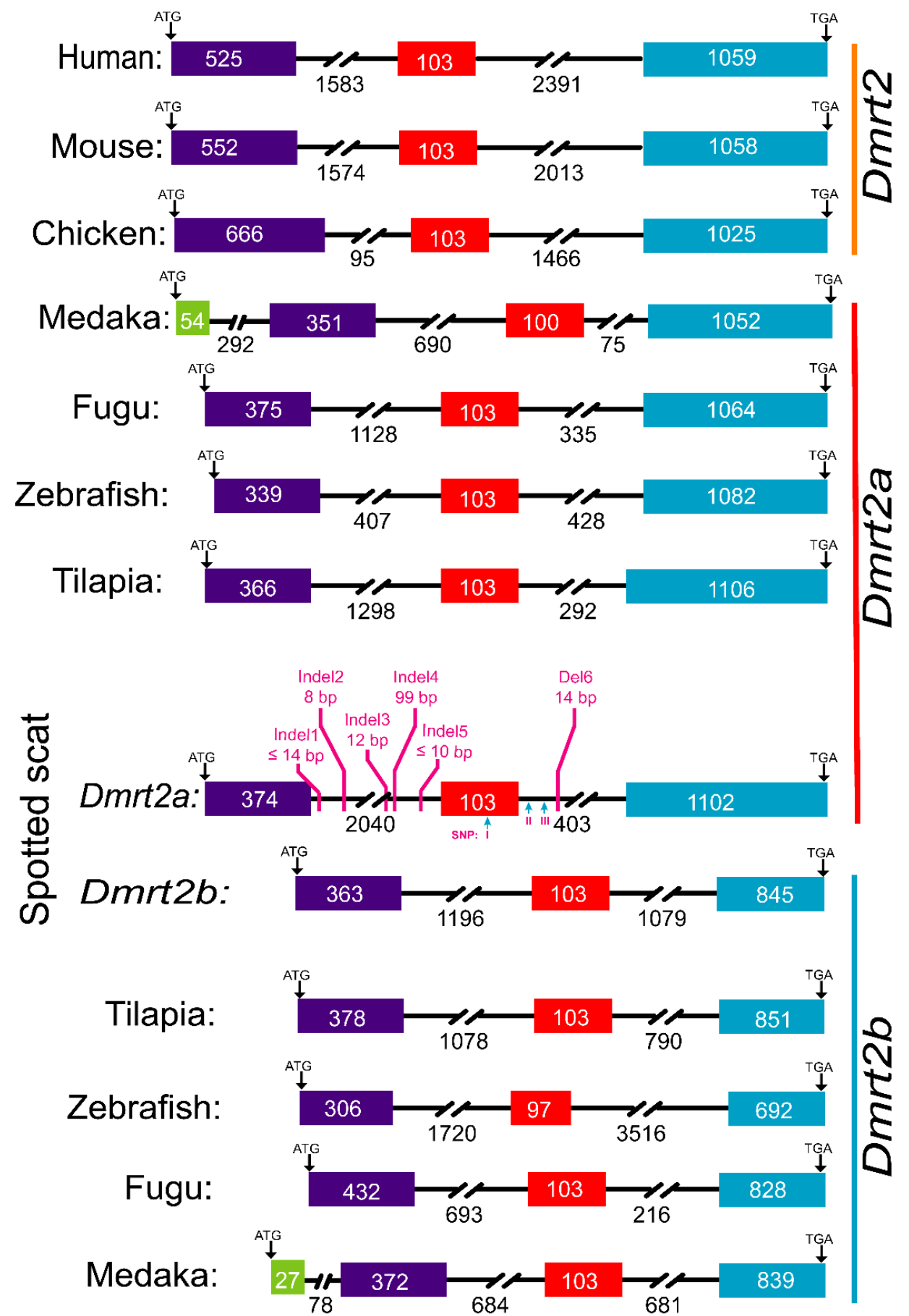

Figure 3. Schematic representation of Dmrt2a and Dmrt2b genes from different species. Boxes and lines indicate exons and introns, respectively. The same colors indicate the same exons. The lengths in bp (base pair) of exons are shown in the boxes, while introns are shown below. Downward arrows indicate start (ATG) and stop (TGA/TAA) codons. Red vertically inclined lines indicate insertions and deletions (indels) on spotted scat Dmrt2a. The polymorphisms in Dmrt2a were obtained from the differences in male and female sequences.

\subsection{The Interspersed Indels and SNPs on Dmrt2a Are Sex-Linked at Different Rates}

Seven primer pairs (markers) flanking the indels, including one on the SNP region, were designed (Figure 3, Table S1) and initially tested on a few individuals (Figure 4 and Figure S2). Marker-1 and marker-5 span indel1 and indel5, respectively, as well as amplified bands that are not distinguishable between males and females. The indels contained in 
marker-1 and marker-5 are preceded by simple sequence repeats (SSR) of at least 16 TG repeats. Interestingly, indel1 and indel5 share similar features and are the first and last indels on intron 1, respectively (Figure 3 and Figure S2).

On the contrary, primers pairs of marker-2, marker- 3 , marker-4, and marker- 6 spanning indel2, indel3, indel4, and del6, respectively, are partially sex-linked (Figure 4). Indel2, indel3, and indel 4 are $8 \mathrm{bp}, 12 \mathrm{bp}$, and $99 \mathrm{bp}$ long, respectively, on intron 1, while del6 is 14 bp long on intron 2 (Figure 4A-D). Marker-2, marker-3, marker-4, and marker-6 showed double bands in most males and single bands in most females. The upper and lower fragments are as follows: marker-2 (a, 147 bp; b, 139 bp); marker-3 (a, 160 bp; b, 148 bp); marker-4 (a, 543 bp; b, 444 bp); marker-6 (a, 158 bp; b, 144 bp). The different intensity levels of the lower and upper bands of marker- 4 could be due to differences in copy number or the lengths of the two fragments. The upper bands of marker- 2 and marker- 6 are found in all male and female individuals. The lower bands of marker- 2 are also present in some males and females, while the lower bands (b $144 \mathrm{bp}$ ) of marker- 6 are restricted to some males. Similarly, the upper band of marker-3 (a $160 \mathrm{bp}$ ) is restricted solely to most males, with the lower (b, $148 \mathrm{bp}$ ) band present in all females (Figure 4).
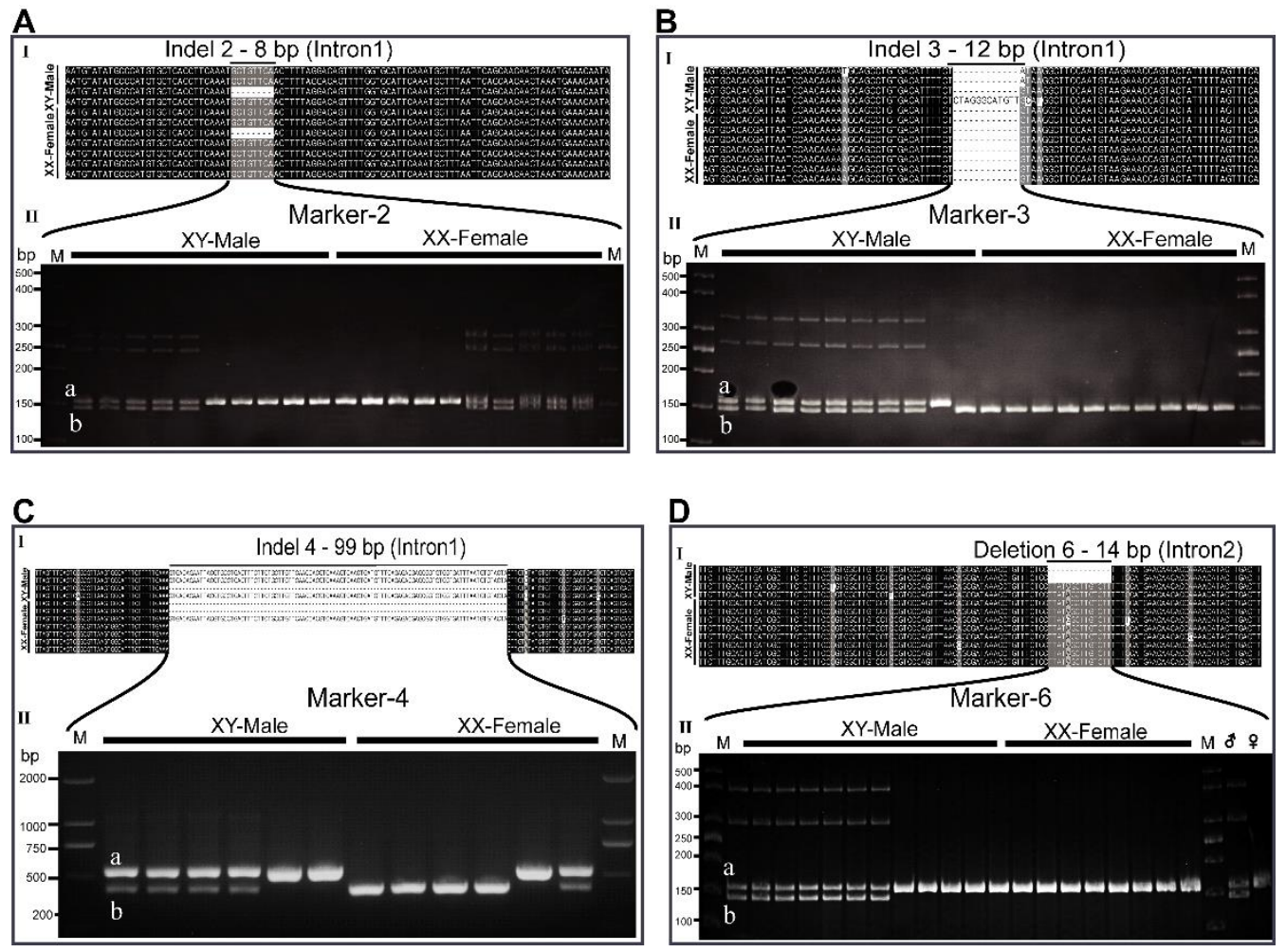

Figure 4. Dmrt2a sequence analysis in spotted scat. (AI) A 8 bp indel in intron 1 of male and female sequence (AII) PAGE gel with primers spanning the indel region was heterozygous (double bands) and homozygous (single bands) in both males and females. (BI) A 12 bp indel in intron 1 of the male sequence. (BII) PAGE gel shows that most males are heterozygous (double bands), while all females are homozygous (single bands). (CI) A 99 bp indel in intron 1 of male and female sequences (CII) Agarose gel electrophoresis reveals heterozygosity and homozygosity in males and females. (DI) A 6 bp deletion in intron 2 of the male sequence. (DII) PAGE gel shows that most males are heterozygous while all females are homozygous. The total number of fish tested with these markers is shown in Tables 1 and 2. a; upper/longer bands, b; lower/shorter bands.

Further analyses of the markers in the four populations indicated different concordance rates (Tables 1 and 2). Marker-1 and marker-5 were not distinguishable by PAGE gel (Figure S2). Marker-2 and marker-4 amplified double and single bands in some males and females from the four different populations. Marker- 3 and marker- 6 consistently amplified 
only single bands (100\%) in females, while double and single bands were present in males. Here, $52 \%$ and $48 \%$ of males amplified with marker- 3 and marker- 6 had double bands. Some markers, such as marker-3 and marker-6, were 100\% consistent with phenotypic sexes of all females from the four different populations. Maker-2 was 100\% consistent with the phenotypic sex of males and females in only the Donghai Dao population. The markers' consistency levels varied within and across populations (Tables 1 and 2), indicating an incomplete sex linkage and a possible evolutionary divergence of Dmrt2a in spotted scat.

Table 2. Comparison of marker-4 and marker-6 with genetic sex of spotted scat from different populations.

\begin{tabular}{|c|c|c|c|c|c|c|}
\hline \multirow[b]{2}{*}{ Population } & \multirow[b]{2}{*}{$\begin{array}{c}\text { Sample Size and } \\
\text { Genotype }\end{array}$} & \multicolumn{2}{|c|}{ Marker-4/Indel4-99 bp (Intron1) } & \multirow[b]{2}{*}{$\begin{array}{l}\text { Sample Size } \\
\text { and Genotype }\end{array}$} & \multicolumn{2}{|c|}{ Marker-6/Del6-14 bp (Intron2) } \\
\hline & & Consistency & $\begin{array}{c}\text { Average } \\
\text { Concordance Rate } \\
(\%)\end{array}$ & & Consistency & $\begin{array}{c}\text { Average } \\
\text { Concordance Rate } \\
(\%)\end{array}$ \\
\hline \multirow{4}{*}{$\begin{array}{l}\text { Donghai } \\
\text { Dao }\end{array}$} & \multirow{2}{*}{ 23ळ } & a (13ఠ్య $)$ & 56.5 & \multirow[b]{2}{*}{$21 \overbrace{}^{\circ}$} & \multirow{2}{*}{$\begin{array}{c}\text { a (3ఠా) } \\
\text { a/b (18ळా) }\end{array}$} & 14.3 \\
\hline & & a/b (10ळ) & 43.5 & & & 85.7 \\
\hline & \multirow{2}{*}{258} & $\mathrm{a} / \mathrm{b}(28)$ & 8 & & \multirow{2}{*}{ a (25우) } & \multirow{2}{*}{100} \\
\hline & & b (23\&) & 92 & 258 & & \\
\hline \multirow{5}{*}{ Beihai } & \multirow{2}{*}{$17 \odot^{\circ}$} & a (9ळ) & 52.9 & \multirow[b]{2}{*}{$15 \odot 5$} & \multirow{2}{*}{$\begin{array}{c}\text { a (7ळ) } \\
\text { a/b (8ळ) }\end{array}$} & 46.7 \\
\hline & & a/b (8ळ) & 47.1 & & & 53.3 \\
\hline & \multirow{3}{*}{138} & a (2\&) & 15.4 & \multirow{3}{*}{158} & \multirow{3}{*}{ a (15\&) } & \multirow{3}{*}{100} \\
\hline & & $\mathrm{a} / \mathrm{b}(68)$ & 46.2 & & & \\
\hline & & b (5\&) & 48.5 & & & \\
\hline \multirow{5}{*}{ Xiashan } & \multirow{2}{*}{ 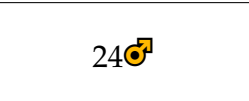 } & a (9ఠా) & 37.5 & \multirow[b]{2}{*}{$25 \odot 5$} & \multirow{2}{*}{$\begin{array}{l}\text { a (16ळூ) } \\
\text { a/b (9ळு) }\end{array}$} & 64 \\
\hline & & $\mathrm{a} / \mathrm{b}$ (15ळ्ఠ) & 62.5 & & & 36 \\
\hline & \multirow{3}{*}{248} & a (4\&) & 16.7 & \multirow{3}{*}{308} & \multirow{3}{*}{ a (30\&) } & \multirow{3}{*}{100} \\
\hline & & $\mathrm{a} / \mathrm{b}(8 \%)$ & 33.3 & & & \\
\hline & & b (12\&) & 50 & & & \\
\hline \multirow{5}{*}{ Zhuhai } & \multirow{2}{*}{$16 \sigma^{\circ}$} & a (4ळு) & 25 & \multirow[b]{2}{*}{ 16ळా } & \multirow{2}{*}{$\begin{array}{l}\text { a (14ळ) } \\
\text { a/b (2ळ) }\end{array}$} & 87.5 \\
\hline & & a/b (12ळ) & 75 & & & 12.5 \\
\hline & \multirow{3}{*}{228} & a (1\&) & 4.5 & & & \\
\hline & & $\mathrm{a} / \mathrm{b}(28)$ & 9.1 & 238 & a $(238)$ & 100 \\
\hline & & b (19\&) & 86.4 & & & \\
\hline & & a (35ळு) & 43.7 & & a (40ळு) & 51.9 \\
\hline & 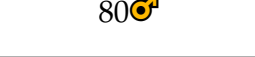 & a/b (45ळ) & 56.3 & 77 마 & a/b (37ळా) & 48.1 \\
\hline TOTAL & & a (78) & 8.3 & & & \\
\hline & 84원 & a/b (18\%) & 21.4 & 938 & a (93우) & 100 \\
\hline & & b (59\&) & 70.2 & & & \\
\hline
\end{tabular}

Note: For marker-4, bands "a", "a/b" and "b" indicate 543 bp, (453 and 444 bp) and 444 bp bands, respectively. For marker-6, bands " $a$ " and "a/b" indicate $158 \mathrm{bp}$, and (158 and $144 \mathrm{bp}$ ) bands, respectively. The " $\mathrm{a}$ " and " $\mathrm{b}$ " inscriptions are shown in Figure 4.

Consistently, marker-7 spanning the three SNPs, named I on exon 2 and II and III on intron 2, also showed different concordance rates within populations (Figure 5). The $500 \mathrm{bp}$ Sanger sequence results of marker-7 revealed heterozygosity (G/A) and (T/C) in XY-males and homozygous (A) and (C) in XX-females at positions I (296) and III (408), respectively. Conversely, at position II (395), XY-male was homozygous while XX-female was heterozygous. Except in one female tail fish from Beihai, which showed heterozygosity (G/A) at position I (296), all females from other populations were homozygous (A) $100 \%$. The highest and lowest population with male heterozygosity rates at positions I and III were Zhuhai $(86.7 \%$ and $86.7 \%$ ) and Donghai Dao (5.3\% and 10.5\%), respectively (Figure $5 \mathrm{C}$ ). 
On the other hand, 100\% of all XY-males from Zhuhai and Xiashan were homozygous (C) at position II (395), with the least homozygosity (52.6\%) observed in the Donghai Dao population. At position $\mathrm{II}$, the $\mathrm{XX}$-female heterozygosity $(\mathrm{C} / \mathrm{T})$ rate ranged from 93.3 in Beihai to $52.6 \%$ in Donghai Dao. Together, these markers suggest that Dmrt $2 a$ is incompletely sex-linked.

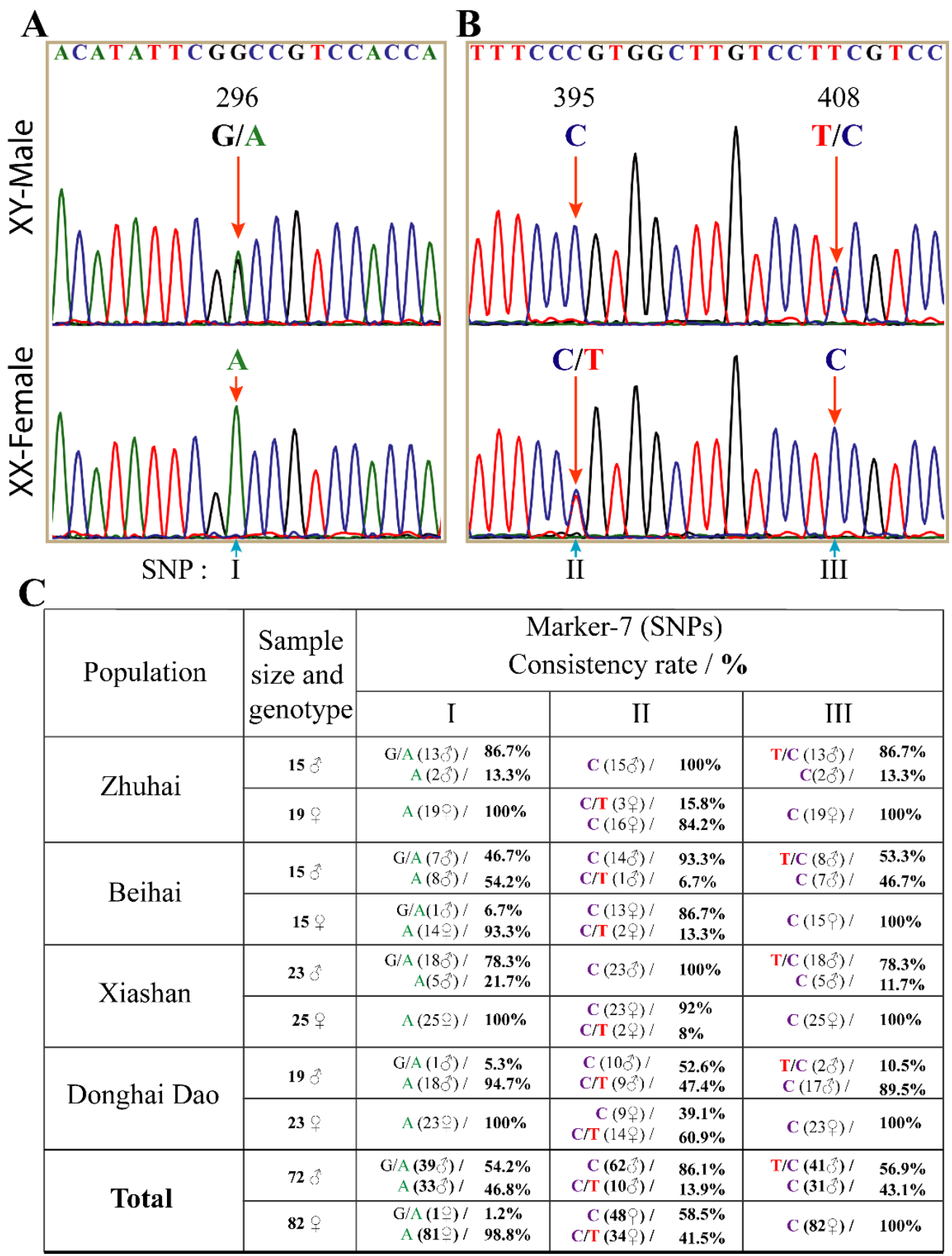

Figure 5. Three sex-linked SNPs in spotted scat Dmrt2a. SNPs in (A) exon2 (I) and (B) intron2, (II and III). (C) Consistency rates of the three SNPs with the genetic sex in different populations. Most males are heterozygous at I (G/A) and III (T/C) and homozygous at II (C), whereas females are homozygous at I (A) and III (C) and heterozygous at II (C/T).

\subsection{Dmrt2a Is Highly Expressed in Spotted Scat Testes}

The tissue distribution of Dmrt $2 a$ and Dmrt $2 b$ mRNA revealed their existence in the gonads and gills of male and female spotted scat. In addition, Dmrt $2 b$ exists moderately in the hypothalamus and is very weak in the spleen of both males and females (Figure 6A). 
A

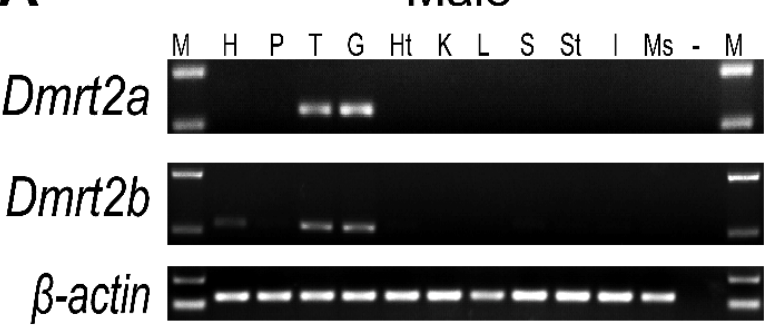

Female
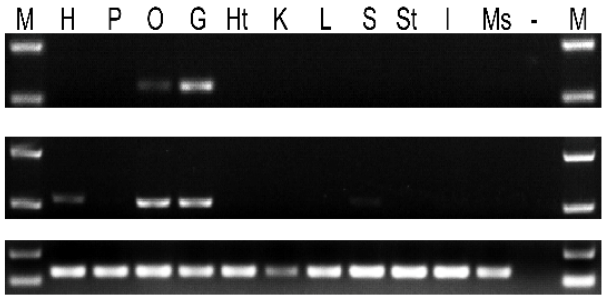

B

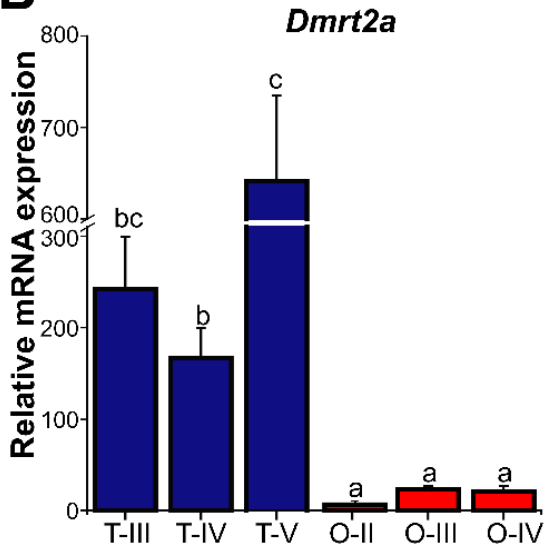

Gonad development stages

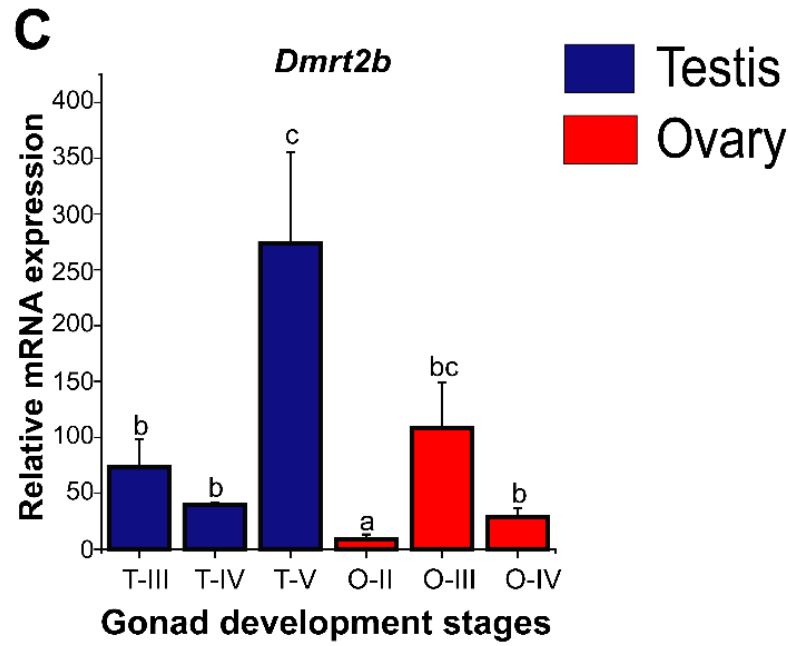

$\mathbf{E}$

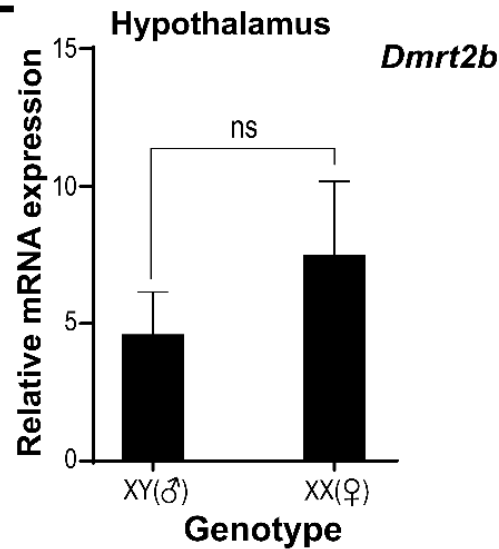

Figure 6. The mRNA expression levels of Dmrt2a and Dmrt2b from different tissues of adult spotted scat by PCR and qPCR. (A) Tissue distribution of Dmrt2a and Dmrt2b. $\beta$-actin was used as an internal control. M, DNA marker; $\mathrm{H}$, hypothalamus; $\mathrm{P}$, pituitary; $\mathrm{T}$, testis; $\mathrm{O}$, ovary; $\mathrm{G}$, gill; $\mathrm{Ht}$, heart; $\mathrm{K}$, kidney; L, liver, S, spleen; St, stomach; I, intestine; Ms, muscle; - , negative control. Gene expression patterns of spotted scat Dmrt $2 a$ and Dmrt $2 b$ mRNA in gonads at different development stages (B,C). Gene expression patterns of spotted scat Dmrt2a and Dmrt2b mRNA in the (D) gills and (E) hypothalamus. Here, $\beta$-actin was used as an internal control for gene normalization, and the $2^{-\Delta \Delta C t}$ method was used in gene expression calculation. The data are expressed as the means \pm standard deviations of at least triplicates. Different letters indicate means with significant differences $(p<0.05)$, and ns indicate no statistically significant difference $(p>0.05)$. " $\mathrm{T}$ " and " $\mathrm{O}$ " indicate testis and ovary, respectively. The roman numerals II, III, IV, and V represent gonad development stages (stage 2, 3, 4, and 5, respectively). $X Y\left(\sigma^{\top}\right)$ and $X X(\%)$ represent male and female, respectively. 
The RT-qPCR gene expression in gonads at different development stages of the testes and ovaries indicated that Dmrt $2 a$ is expressed at significantly higher levels in the testes than in the ovaries $(p<0.05)$ (Figure 6B), while Dmrt $2 b$ is more highly expressed in late-stage testes than ovaries (Figure 6C). In the ovaries, Dmrt2a is expressed similarly in all stages (stages II, III, and IV), whereas Dmrt2b is significantly expressed at the middle stage (stage III). In the gills and hypothalamus of male and female spotted scat, Dmrt $2 a$ and Dmrt $2 b$ did not exhibit significantly biased expression (Figure 6D,E). Similarly, Dmrt2b was almost equally expressed in the hypothalamus of both males and females (Figure 6D). Together, Dmrt $2 a$ is more highly expressed during testes development and less so in the ovaries.

\subsection{The Expression of Dmrt2a in Spotted Scat Gonads}

Gonadal transcriptome analysis of Dmrt1, Dmrt2a, and Dmrt2b from spotted scat, Hainan medaka (Oryzias curvinotus), silver sillago (Sillago sihama), Nile tilapia (Oreochromis niloticus), Hong Kong catfish (Clarias fuscus), and spot-fin porcupine fish (Diodon hystrix) was performed to determine their expression patterns. The results show that Dmrt1 consistently expressed higher levels in the testes than in the ovaries (Figure 7A-F). Dmrt2a was highly expressed in the testes of spotted scat, consistent with the results from the qPCR test. Additionally, Dmrt2a was expressed highly in the testes of Hainan medaka and ovaries of silver sillago and tilapia (Figure 7a,b). Interestingly, while Dmrt2b was expressed highly in spotted scat, silver sillago, and Nile tilapia testes, it was not detectable in Hainan medaka (Figure 7a-d). The higher expression of Dmrt2a in the testes of Hainan medaka might have been influenced by the undetectable Dmrt2b. On the contrary, neither Dmrt $2 a$ and Dmrt $2 b$ transcripts were detectable in Hong Kong catfish and spot-fine porcupine fish annotations.
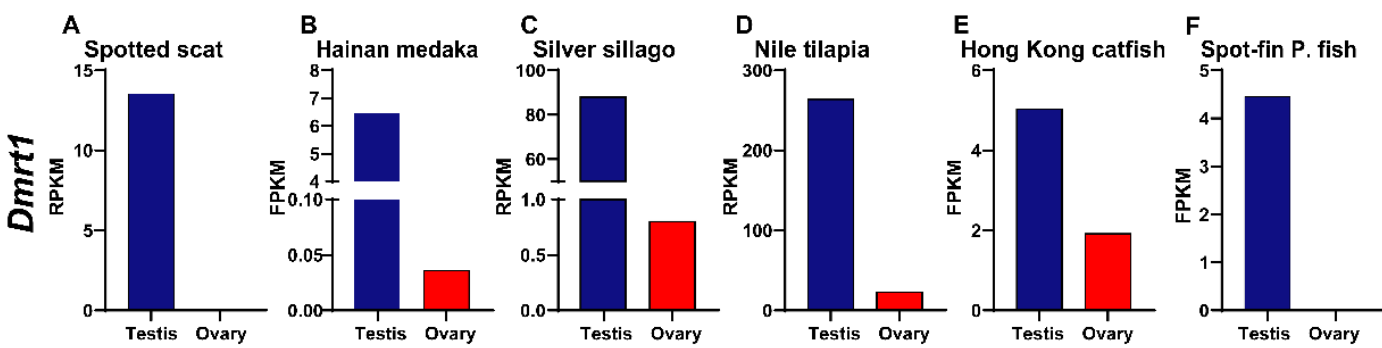

Spotted scat

b

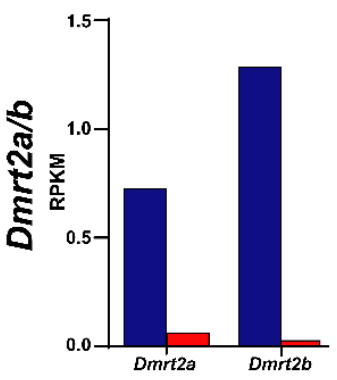

Hainan medaka

c
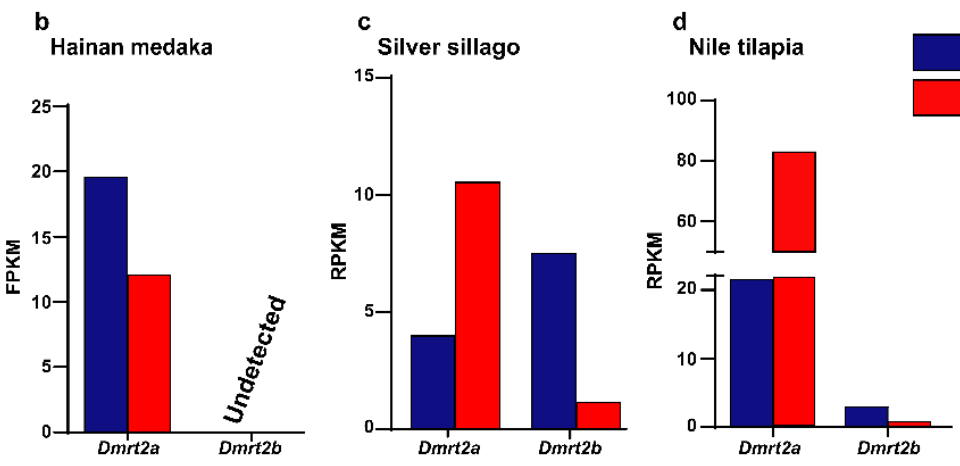

Figure 7. Gene expression in RPKM/FPKM obtained from gonad transcriptome data of $(\mathbf{A}, \mathbf{a})$ spotted scat [36], (B,b) Hainan medaka [38], (C,c) silver sillago [39], (D,d) Nile tilapia [40], (E) Hong Kong catfish [41], and (F) spot-fine porcupine fish [42]. Dmrt1 is consistently expressed at higher levels in all testes. Dmrt2a is expressed at higher levels in the testes of spotted scat and Hainan medaka and the ovaries of tilapia and silver sillago. Dmrt2b, on the other hand, is expressed at higher levels in the testes of spotted scat and tilapia. Dmrt $2 a$ and Dmrt $2 b$ were not detectable in the transcriptome data for Hong Kong catfish and Spot-fin porcupine fish.

Dmrt2a ORF was again blasted in a different RNA-seq data of 6 male and female spotted scat samples. The expression values of Dmrt $2 a$ transcript in reads and FPKM were extracted (Figure S3A,i). Although the expression of Dmrt2a seems low, it was higher in 
males than in females (Figure S3A,ii), similar to Figure 7a. The results show that Dmrt2a expression differs even within males. Similarly, the proportion of G/A sub-types of the SNP on exon 2 (SNP I) varied within males, with the proportions of $\mathrm{G}$ allele $(63.4 \%)$ being higher than the A allele (36.6\%) (Figure S3B), while either G or A was not present in some males. The A/G sub-types are variant sequences in males and females. Therefore, the $G$ and $A$ sub-types occur at different rates in males and females and might represent differential expression even within males.

\section{Discussion}

The whole-genome sequencing showed that Dmrt2a, but not Dmrt2b, is close to the candidate sex determination gene (Dmrt1) in spotted scat. Hence, Dmrt2a is a good model for demonstrating the gene sequence differentiation and sexually biased expression genes in the young sex chromosome.

4.1. The Spotted Scat and the Incomplete Sex-Linked Dmrt2a Gene Are Excellent Models to Study the Evolution of Sex Chromosomes and the Differentiation of Sex-Linked Genes

The evolution of sex chromosomes suggests that recombination suppression leads to the degeneration of the heterogametic chromosome, such as the $\mathrm{Y}$ chromosome in mammals and the $\mathrm{W}$ chromosome in most birds. The sex chromosomes of mammals and birds are highly differentiated, with a very long evolutionary process. The mammalian Y chromosome has a long evolutionary history of more than 150 million years, whereas the $\mathrm{W}$ chromosome arose approximately 140 million years ago in the bird ancestor [43-45]. Fishes have both XY and ZW sex chromosomes systems, with ZW being the most differentiated [46]. The spotbanded scat (Selenotoca multifasciata) is closely related to spotted scat and diverged more than 13 million years ago, sharing the same candidate sex determination gene (Dmrt1) ([3] unpublished data). This implies that the spotted scat sex chromosome may be young and an excellent model to study the evolution of sex chromosomes in vertebrates.

Markers designed on the Dmrt2a transcript indicate that Dmrt2a is partially sex-linked in spotted scat. The spotted scat Dmrt $2 a$ exhibits varying sequence variations with several insertions and deletions (indels) and single-nucleotide polymorphisms (SNPs) between males and females. However, the sequence of Dmrt $2 a$ is functional, unlike Dmrt3 $\triangle-Y$ and $D m r t 1 b$, although differences might be present in the promoter region. XX spotted scat lack a normal Dmrt1, yet growth is not affected, indicating that Dmrt1 is not essential for survival. Consistently, Dmrt1 - / - zebrafish grow like normal female [47]. Additionally, Dmrt3 gene knockouts studies showed that it is not critical for mouse survival [48]. Therefore, the dysfunctional mutation on the sex-linked region will most probably occur on genes whose functions are not essential for the survival of both sexes or the sexual maintenance of one sex. Hence, the spotted scat Dmrt $2 a$ might have a vital role in the developmental process. Additionally, the conservation differences between Dmrt1, Dmrt3, and Dmrt2a might be due to the effect of the gene dosage, since correct dosage is required for the proper functioning of the gene, or specialization of the truncated copies of Dmrt1 and Dmrt3 might be necessary for regulating normal gene copies $[49,50]$.

Markers spanning the indels and SNPs tested on four populations indicated that the mutations are sex-linked at different rates, with males characterized by high heterogeneity. The mutations may be variably sex-linked in different populations because of the genetic variation required for evolutionary novelty and adaptation [51]. Interestingly, most of these mutations are found in the intronic regions, which is plausibly why there was no effect on the gene's translation. Additionally, the high polymorphism in males can be explained in alternative ways as follows: (1) all indels originated from Dmrt2a on the Y chromosome and rare crossing-over transferred the mutated alleles onto the $X$ chromosome; (2) the Dmrt $2 a$ introns might contain regulatory elements that in females play a more critical role in viability or reproduction than in males. The expression of Dmrt $2 a$ in the gonads at the early 
stages of development should be investigated. Additionally, future research is required to identify the regulatory regions.

It is worth noting that Dmrt3 is positioned closer to the candidate sex determination gene (Dmrt1) (Figure 1 and Table S3), likely resulting in its quick differentiation. On the other hand, Dmrt2a is farther away from Dmrt1, which means more time may be needed for the differentiation to occur. Although in zebrafish Dmrt2a mutation is not lethal in experimental conditions [52], we cannot rule out the possibility of Dmrt2a exerting an essential function in developmental processes or adaptable characteristics in the natural environment. The critical function of Dmrt2a might restrict the accumulation of the dysfunctional mutation on its sequences. As such, the spotted scat Dmrt2a sequence variation will be monitored in the future.

\subsection{Reason for the Sexually Dimorphic Expression of Dmrt2 in the Gonads of Spotted Scat}

Gene expression studies have gained research interest in recent years because of the importance of understanding the changes in biological processes. Gene expression can provide a snapshot of actively expressed genes and transcripts in developmental pathways or responses or adaptions to new conditions. In recent years, most researchers have been interested in genes that exhibit sexually dimorphic expression patterns. Fortunately, technological advancements such as transcriptome analysis have made identifying gonadal sexual biased genes easy. Numerous sex-biased genes have since been identified in many other species [41,42,53-55], including Nile tilapia [40] and spotted scat [36]. Meanwhile, most of these studies have focused on gonadal gene expression, with little or no interest in the possible mechanism leading to sex difference. Ideally, sex-linked genes might show sexually biased expression $[3,36,56]$.

The spotted scat Dmrt2a exhibits sex-biased expression. However, the sexually dimorphic expression of Dmrt2a might not necessarily be due to it being sex-linked. Autosomal Dmrt2a of Hainan medaka, silver sillago, and Nile tilapia also showed sexually dimorphic expressions. Several factors may affect gene expression patterns. For instance, transcriptional regulation can affect the pattern of gene expression [57]. In addition, epigenetic changes in the actual DNA sequence can also affect gene expression. In fighting fish, Dmrt1 shows male-biased gonadal expression, while the reduced expression in female is caused by epigenetic changes [58]. This epigenetic change is induced by the Drbx1 gene at the promoter region of Dmrt1 [58]. The spotted scat Drmt2a promotor region also has several polymorphisms. It is unclear whether the sex-biased expression of the spotted scat Dmrt2a is caused by the polymorphism at the promoter region or DNA methylation. Additionally, upstream genes are promoter sequences, natural regulators of gene expression, and major gene expression regulatory elements [59]. Therefore, further studies such as epigenetic modification, ATAC sequencing, and $\mathrm{X}$ and $\mathrm{Y}$ sequence variation analysis are needed to elucidate the regulators of Dmrt2a expression in spotted scat.

\section{Conclusions}

Herein, the spotted scat chromosome is not old, making it an excellent model to study the evolution of sex chromosomes in teleosts. In spotted scat, Dmrt2a is positioned close to the sex-specific Dmrt3 and Dmrt1 with the three genes spanning across an estimated distance of $40 \mathrm{~kb}$ on the sex chromosome. The Dmrt2a is highly mutated at the non-coding region, with males exhibiting high heterogeneity. The results infer that Dmrt2a is partially sex-linked in spotted scat. Dmrt2a is functional and might regulate other developmental processes, or it is yet to be differentiated in spotted scat. Therefore, Dmrt2a is an excellent model for studying sex-linked gene differentiation during the evolution of vertebrates. The expression patterns of Dmrt2a in gonads fluctuate among different species, suggesting different functions in different species. Hence, studies to elucidate the function of Dmrt2a in spotted scat will bring to bear its role in developmental processes. 
Supplementary Materials: The following supporting information can be downloaded at: https: / / www.mdpi.com/article/10.3390/ani12050613/s1. Figure S1: Nucleotide and deduced amino acid (aa) sequences of spotted scat Dmrt2a (A) and Dmrt2b (B). Nucleotides and amino acid (aa) sequences are numbered to the right. Rectangle indicates the conserved DM domain region. The putative nuclear localization signals (NLSs) are highlighted in grey. Downward and upward arrows indicate start and stop ${ }^{*}$ ) codons and conserved cysteine and histidine residues, respectively. Figure S2: Dmrt $2 a$ sequence analysis in spotted scat. (AI) At most $14 \mathrm{bp}$ indels in intron 1 of male and female sequences (AII), PAGE gel with primers spanning the indel region (marker-1) did not show distinguishable bands in males and females. (BI) At most $10 \mathrm{bp}$ indels in intron 1 of male and female sequences (BII), PAGE gel with primers spanning the indel region (marker-5) did not show distinguishable bands between males and females. At least 16 TG single sequence repeats (SSR-1 and SSR-2) preceded indel 1 and indel 5. The indel 1 and the indel 5 are positioned first and last on intron1. Table S1: Primer sequences used in this study. Table S2: NCBI and Ensembl sequence IDs of Dmrt proteins used in this study. Figure S3. A) Dmrt2a transcript expression by transcriptome analysis. i) Dmrt2a FPKM and reads values from 6 male and 6 female transcriptome data. ii) Graph of average FPKM values and reads numbers from the 6 males and females in "i" above. B) The proportion of $\mathrm{G}$ and A sub-types in six XY-males (male 1 - 6). The SNP region (SNP: I) on the Exon 2 of Dmrt2a transcript was used as a querry sequence to blast the row RNA-seq data of $6 \mathrm{XY}$-males using blastX. The proportion of clean reads with either $\mathrm{G}$ or A were determined. Male 1 has very low reads, and the SNP site was not found. Male 2 and (4 and 5) did not have $G$ and A alleles, respectively. On average, the proportion of the $\mathrm{G}$ allele is more $(63.4 \%)$ than $\mathrm{A}(36.6 \%)$

Author Contributions: Conceptualization, U.F.M., D.-N.J. and G.-L.L.; methodology, U.F.M. and D.-N.J.; investigation, U.F.M., D.A. and Y.-Q.H.; writing—original draft preparation, U.F.M.; writingreview and editing, U.F.M. and D.-N.J.; funding acquisition, D.-N.J. and G.-L.L. All authors have read and agreed to the published version of the manuscript.

Funding: This study was supported by grants from the Key Project of "Blue Granary Science and Technology Innovation" of the Ministry of Science and Technology (2018YFD0901203); the National Natural Science Foundation of China (Nos. 32172971); and Guangdong Basic and Applied Basic Research Foundation (2019A1515012042 and 2021A1515010430).

Institutional Review Board Statement: The study was conducted in accordance with the guidelines of the Animal Research and Ethics Committee of the Institute of Aquatic Economic Animals, Guangdong Ocean University, China (201903004). The study did not require approval by the local ethics committee.

Informed Consent Statement: Not applicable.

Data Availability Statement: Not applicable.

Conflicts of Interest: The authors declare no conflict of interest.

\section{References}

1. Bachtrog, D.; Mank, J.E.; Peichel, C.L.; Kirkpatrick, M.; Otto, S.P.; Ashman, T.L.; Hahn, M.W.; Kitano, J.; Mayrose, I.; Ming, R.; et al. Sex determination: Why so many ways of doing it? PLoS Biol. 2014, 12, 1-13. [CrossRef] [PubMed]

2. Mei, J.; Gui, J.F. Genetic basis and biotechnological manipulation of sexual dimorphism and sex determination in fish. Sci. China Life Sci. 2015, 58, 124-136. [CrossRef]

3. Mustapha, U.F.; Jiang, D.N.; Liang, Z.H.; Gu, H.-T.; Yang, W.; Chen, H.P.; Deng, S.; Wu, T.L.; Tian, C.-X.X.; Zhu, C.H.; et al. Male-specific dmrt1 is a candidate sex determination gene in spotted scat (Scatophagus argus). Aquaculture 2018, 495, 351-358. [CrossRef]

4. $\quad$ Bao, L.; Tian, C.; Liu, S.; Zhang, Y.; Elaswad, A.; Yuan, Z.; Khalil, K.; Sun, F.; Yang, Y.; Zhou, T.; et al. The Y Chromosome sequence of the channel catfish suggests novel sex determination mechanisms in teleost fish. BMC Biol. 2019, 17, 1-16. [CrossRef]

5. Li, M.; Sun, Y.; Zhao, J.; Shi, H.; Zeng, S.; Ye, K.; Jiang, D.; Zhou, L.; Sun, L.; Tao, W.; et al. A tandem duplicate of anti-müllerian hormone with a missense SNP on the Y chromosome is essential for male sex determination in nile tilapia, Oreochromis niloticus. PLoS Genet. 2015, 11, 1-23. [CrossRef]

6. Pan, Q.; Feron, R.; Yano, A.; Jouanno, E.; Wen, M.; Bobe, J.; Concordet, J.-P.; Journot, L.; Klopp, C.; Schartl, M.; et al. Identification of the master sex determining gene in northern pike (Esox lucius) reveals restricted sex. bioRxiv 2019, 15, 549527. [CrossRef]

7. Kikuchi, K.; Hamaguchi, S. Novel sex-determining genes in fish and sex chromosome evolution. Dev. Dyn. 2013, 242, 339-353. [CrossRef] 
8. Martínez, P.; Viñas, A.M.; Sánchez, L.; Díaz, N.; Ribas, L.; Piferrer, F. Genetic architecture of sex determination in fish: Applications to sex ratio control in aquaculture. Front. Genet. 2014, 5, 1-13. [CrossRef] [PubMed]

9. Charlesworth, D.; Charlesworth, B.; Marais, G. Steps in the evolution of heteromorphic sex chromosomes. Heredity 2005, 95, 118-128. [CrossRef] [PubMed]

10. Murphy, M.W.; Lee, J.K.; Rojo, S.; Gearhart, M.D.; Kurahashi, K.; Banerjee, S.; Loeuille, G.A.; Bashamboo, A.; McElreavey, K.; Zarkower, D.; et al. An ancient protein-DNA interaction underlying metazoan sex determination. Nat. Struct. Mol. Biol. 2015, 22, 442-451. [CrossRef]

11. Dong, J.; Li, J.; Hu, J.; Sun, C.; Tian, Y.; Li, W.; Yan, N.; Sun, C.; Sheng, X.; Yang, S.; et al. Comparative genomics studies on the dmrt gene family in fish. Front. Genet. 2020, 11, 563947. [CrossRef] [PubMed]

12. Johnsen, H.; Andersen, $\varnothing$. Sex dimorphic expression of five dmrt genes identified in the atlantic cod genome. The fish-specific Dmrt2b diverged from Dmrt2a before the fish whole-genome duplication. Gene 2012, 505, 221-232. [CrossRef]

13. Su, L.; Zhou, F.; Ding, Z.; Gao, Z.; Wen, J.; Wei, W.; Wang, Q.; Wang, W.; Liu, H. Transcriptional variants of Dmrt1 and expression of four dmrt genes in the blunt snout bream, Megalobrama amblycephala. Gene 2015, 573, 205-215. [CrossRef] [PubMed]

14. Portela-Bens, S.; Merlo, M.A.; Rodríguez, M.E.; Cross, I.; Manchado, M.; Kosyakova, N.; Liehr, T.; Rebordinos, L. Integrated gene mapping and synteny studies give insights into the evolution of a sex proto-chromosome in Solea senegalensis. Chromosoma 2017, 126, 261-277. [CrossRef] [PubMed]

15. Raghuveer, K.; Senthilkumaran, B. Identification of multiple Dmrt1s in catfish: Localization, dimorphic expression pattern, changes during testicular cycle and after methyltestosterone treatment. J. Mol. Endocrinol. 2009, 42, 437-448. [CrossRef] [PubMed]

16. Li, L.; Mao, A.; Wang, P.; Ning, G.; Cao, Y.; Wang, Q. Endodermal pouch-expressed Dmrt2b Is important for pharyngeal cartilage formation. Biol. Open 2018, 7, bio035444. [CrossRef]

17. Lyu, Q.; Hu, J.; Yang, X.; Liu, X.; Chen, Y.; Xiao, L.; Liu, Y.; Wang, Q.; Chen, J.; Huang, M.; et al. Expression profiles of dmrts and foxls during gonadal development and sex reversal induced by $17 \alpha$-methyltestosterone in the orange-spotted grouper. Gen. Comp. Endocrinol. 2019, 274, 26-36. [CrossRef]

18. Wexler, J.R.; Plachetzki, D.C.; Kopp, A. Pan-metazoan phylogeny of the DMRT gene family: A framework for functional studies Dev. Genes Evol. 2014, 224, 175-181. [CrossRef]

19. Hong, C.-S.; Park, B.-Y.; Saint-Jeannet, J.-P. The function of dmrt genes in vertebrate development: It is not just about sex. Dev. Biol. 2007, 310, 1-9. [CrossRef]

20. Brunner, B. Genomic organization and expression of the doublesex-Related gene cluster in vertebrates and detection of putative regulatory regions for DMRT1. Genomics 2001, 77, 8-17. [CrossRef]

21. Kim, S.; Kettlewell, J.R.; Anderson, R.C.; Bardwell, V.J.; Zarkower, D. Sexually dimorphic expression of multiple doublesex-related genes in the embryonic mouse gonad. Gene Expr. Patterns 2003, 3, 77-82. [CrossRef]

22. Kondo, M.; Froschauer, A.; Kitano, A.; Nanda, I.; Hornung, U.; Volff, J.-N.; Asakawa, S.; Mitani, H.; Naruse, K.; Tanaka, M.; et al Molecular cloning and characterization of DMRT genes from the medaka oryzias latipes and the platyfish Xiphophorus maculatus. Gene 2002, 295, 213-222. [CrossRef]

23. Winkler, C.; Hornung, U.; Kondo, M.; Neuner, C.; Duschl, J.; Shima, A.; Schartl, M. Developmentally regulated and non-sexspecific expression of autosomal dmrt genes in embryos of the medaka fish (Oryzias latipes). Mech. Dev. 2004, 121, 997-1005. [CrossRef] [PubMed]

24. Zhang, X.; Wang, H.; Li, M.; Cheng, Y.; Jiang, D.; Sun, L.; Tao, W.; Zhou, L.; Wang, Z.; Wang, D. Isolation of doublesex- and Mab-3-related transcription factor 6 and its involvement in spermatogenesis in tilapia1. Biol. Reprod. 2014, 91, 1-10. [CrossRef] [PubMed]

25. Ottolenghi, C.; Fellous, M.; Barbieri, M.; McElreavey, K. Novel paralogy relations among human chromosomes support a link between the phylogeny of doublesex-related genes and the evolution of sex determination. Genomics 2002, 79, 333-343. [CrossRef] [PubMed]

26. Zhou, X.; Li, Q.; Lu, H.; Chen, H.; Guo, Y.; Cheng, H.; Zhou, R. Fish specific duplication of Dmrt2: Characterization of zebrafish Dmrt2b. Biochimie 2008, 90, 878-887. [CrossRef]

27. Zheng, Y.; Liang, H.; Xu, P.; Li, M.; Wang, Z. Molecular cloning of Pcc-Dmrt1s and their specific expression patterns in pengze crucian carp (Carassius auratus var. pengze) affected by $17 \alpha$-methyltestosterone. Fish Physiol. Biochem. 2014, 40, 1141-1155. [CrossRef]

28. Yu, F.-F.; Wang, M.-F.; Zhou, L.; Gui, J.-F.; Yu, X.-Y. Molecular cloning and expression characterization of Dmrt2 in akoya pearl oysters, Pinctada Martensii. J. Shellfish Res. 2011, 30, 247-254. [CrossRef]

29. Lourenço, R.; Lopes, S.S.; Saúde, L. Left-right function of Dmrt2 genes is not conserved between zebrafish and mouse. PLoS ONE 2010, 5, e14438. [CrossRef]

30. Seo, K.W.; Wang, Y.; Kokubo, H.; Kettlewell, J.R.; Zarkower, D.A.; Johnson, R.L. Targeted disruption of the dm domain containing transcription factor Dmrt2 reveals an essential role in somite patterning. Dev. Biol. 2006, 290, 200-210. [CrossRef]

31. Sheng, Y.; Chen, B.; Zhang, L.; Luo, M.; Cheng, H.; Zhou, R. Identification of dmrt genes and their up-regulation during gonad transformation in the swamp eel (Monopterus albus). Mol. Biol. Rep. 2014, 41, 1237-1245. [CrossRef] [PubMed]

32. Huang, Y.; Jiang, D.; Li, M.; Mustapha, U.F.; Tian, C.; Chen, H.; Huang, Y.; Deng, S.; Wu, T.; Zhu, C.; et al. Genome survey of male and female spotted scat (Scatophagus argus). Animals 2019, 9, 1117. [CrossRef] [PubMed] 
33. Huang, Y.; Mustapha, U.F.; Huang, Y.; Tian, C.; Yang, W.; Chen, H.; Deng, S.; Zhu, C.; Jiang, D.; Li, G. A chromosome-Level genome assemblyof the spotted scat (Scatophagus Argus). Genome Biol. Evol. 2021, 13, evab092. [CrossRef] [PubMed]

34. Jiang, D.N.; Mustapha, U.F.; Shi, H.J.; Huang, Y.Q.; Si-Tu, J.X.; Wang, M.; Deng, S.P.; Chen, H.P.; Tian, C.X.; Zhu, C.-H.C.H.; et al. Expression and transcriptional regulation of Gsdf in spotted scat (Scatophagus argus). Comp. Biochem. Physiol. Part B Biochem. Mol. Biol. 2019, 233, 35-45. [CrossRef] [PubMed]

35. Yang, W.; Chen, H.; Cui, X.; Zhang, K.; Jiang, D.; Deng, S.; Zhu, C.; Li, G. Sequencing, de novo assembly and characterization of the spotted scat Scatophagus argus (Linnaeus 1766) transcriptome for discovery of reproduction related genes and SSRs. J. Oceanol. Limnol. 2018, 36, 1329-1341. [CrossRef]

36. He, F.X.; Jiang, D.N.; Huang, Y.Q.; Mustapha, U.F.; Yang, W.; Cui, X.F.; Tian, C.X.; Chen, H.P.; Shi, H.J.; Deng, S.P.; et al. Comparative transcriptome analysis of male and female gonads reveals sex-biased genes in spotted scat (Scatophagus argus). Fish Physiol. Biochem. 2019, 45, 1963-1980. [CrossRef]

37. Mustapha, U.F.; Huang, Y.; Huang, Y.-Q.; Assan, D.; Shi, H.-J.; Jiang, M.-Y.; Deng, S.-P.; Li, G.-L.; Jiang, D.-N. Gonadal development and molecular analysis revealed the critical window for sex differentiation, and E2 reversibility of XY-male spotted scat, scatophagus argus. Aquaculture 2021, 544, 737147. [CrossRef]

38. Dong, Z.; Li, X.; Yao, Z.; Wang, C.; Guo, Y.; Wang, Q.; Shao, C.; Wang, Z. Oryzias curvinotus in sanya does not contain the male sex- determining gene dmy. Animals 2021, 11, 1327. [CrossRef]

39. Tian, C.; Li, Z.; Dong, Z.; Huang, Y.; Du, T.; Chen, H.; Jiang, D.; Deng, S.; Zhang, Y.; Wanida, S.; et al. Transcriptome analysis of male and female mature gonads of silver sillago (Sillago sihama). Genes 2019, 10, 129. [CrossRef]

40. Tao, W.; Yuan, J.; Zhou, L.; Sun, L.; Sun, Y.; Yang, S.; Li, M.; Zeng, S.; Huang, B.; Wang, D. Characterization of gonadal transcriptomes from nile tilapia (Oreochromis niloticus) reveals differentially expressed genes. PLoS ONE 2013, 8, 63604. [CrossRef]

41. Lin, X.; Zhou, D.; Zhang, X.; Li, G.; Zhang, Y.; Huang, C.; Zhang, Z.; Tian, C. A First insight into the gonad transcriptome of Hong Kong catfish (Clarias fuscus). Animals 2021, 11, 1131. [CrossRef]

42. Chen, H.; Li, Z.; Wang, Y.; Huang, H.; Yang, X.; Li, S.; Yang, W.; Li, G. Comparison of gonadal transcriptomes uncovers reproduction-related genes with sexually dimorphic expression patterns in diodon hystrix. Animals 2021, 11, 1042. [CrossRef]

43. Graves, J.A.M. The rise and fall of SRY. Trends Genet. 2002, 18, 259-264. [CrossRef]

44. Cortez, D.; Marin, R.; Toledo-Flores, D.; Froidevaux, L.; Liechti, A.; Waters, P.D.; Grützner, F.; Kaessmann, H. Origins and functional evolution of $Y$ chromosomes across mammals. Nature 2014, 508, 488-493. [CrossRef] [PubMed]

45. Graves, M.J.A. Evolution of the testis-determining gene-The rise and fall of SRY. Novartis Found. Symp. 2002, 244, 86-101. [CrossRef]

46. De Bello Cioffi, M.; Kejnovsk, E.; Marquioni, V.; Poltronieri, J.; Molina, W.F.; Diniz, D.; Bertollo, L.A.C. The key role of repeated DNAs in sex chromosome evolution in two fish species with ZW sex chromosome system. Mol. Cytogenet. 2012, 5, 1-7. [CrossRef] [PubMed]

47. Webster, K.A.; Schach, U.; Ordaz, A.; Steinfeld, J.S.; Draper, B.W.; Siegfried, K.R. Dmrt1 Is Necessary for male sexual development in zebrafish. Dev. Biol. 2017, 422, 33-46. [CrossRef] [PubMed]

48. Inui, M.; Tamano, M.; Kato, T.; Takada, S. CRISPR/Cas9-Mediated simultaneous knockout of Dmrt1 and Dmrt3 does not recapitulate the 46,XY gonadal dysgenesis observed in 9p24.3 deletion patients. Biochem. Biophys. Rep. 2017, 9, 238-244. [CrossRef]

49. Curzon, A.Y.; Shirak, A.; Dor, L.; Zak, T.; Perelberg, A.; Seroussi, E.; Ron, M. A duplication of the anti-müllerian hormone gene is associated with genetic sex determination of different oreochromis niloticus strains. Heredity 2020, 125, 317-327. [CrossRef]

50. Liu, X.; Dai, S.; Wu, J.; Wei, X.; Zhou, X.; Chen, M.; Tan, D.; Pu, D.; Li, M.; Wang, D. Roles of anti-müllerian hormone and its duplicates in sex determination and germ cell proliferation of nile tilapia. Genetics 2021, iyab237. [CrossRef]

51. Jiang, X.; Mu, B.; Huang, Z.; Zhang, M.; Wang, X.; Tao, S. Impacts of Mutation effects and population size on mutation rate in asexual populations: A simulation study. BMC Evol. Biol. 2010, 10, 1-13. [CrossRef] [PubMed]

52. Pinto, R.A.; Almeida-Santos, J.; Lourenço, R.; Saúde, L. Identification of Dmrt2a downstream genes during zebrafish early development using a timely controlled approach. BMC Dev. Biol. 2018, 18, 4. [CrossRef]

53. Ebbing, A.; Vértesy, Á.; Betist, M.C.; Spanjaard, B.; Junker, J.P.; Berezikov, E.; van Oudenaarden, A.; Korswagen, H.C. Spatial transcriptomics of C. elegans males and hermaphrodites identifies sex-specific differences in gene expression patterns. Dev. Cell 2018, 47, 801-813.e6. [CrossRef]

54. Lee, S.L.J.; Horsfield, J.A.; Black, M.A.; Rutherford, K.; Fisher, A.; Gemmell, N.J. Histological and transcriptomic effects of $17 \alpha$-methyltestosterone on zebrafish gonad development. BMC Genom. 2017, 18, 557. [CrossRef] [PubMed]

55. Ribas, L.; Robledo, D.; Gómez-Tato, A.; Viñas, A.; Martínez, P.; Piferrer, F. Comprehensive transcriptomic analysis of the process of gonadal sex differentiation in the turbot (Scophthalmus maximus). Mol. Cell. Endocrinol. 2016, 422, 132-149. [CrossRef]

56. Kobayashi, T.; Matsuda, M.; Kajiura-Kobayashi, H.; Suzuki, A.; Saito, N.; Nakamoto, M.; Shibata, N.; Nagahama, Y. Two DM domain genes, DMY and DMRT1, involved in testicular differentiation and development in the medaka, Oryzias latipes. Dev. Dyn. 2004, 231, 518-526. [CrossRef] [PubMed]

57. Lee, T.I.; Young, R.A. Transcriptional regulation and its misregulation in disease. Cell 2013, 152, 1237. [CrossRef]

58. Wang, L.; Sun, F.; Wan, Z.Y.; Yang, Z.; Tay, Y.X.; Lee, M.; Ye, B.; Wen, Y.; Meng, Z.; Fan, B.; et al. Transposon-induced epigenetic silencing in the $\mathrm{X}$ chromosome as a novel form of dmrt1 expression regulation during sex determination in the fighting fish. BMC Biol. 2022, 20, 1-16. [CrossRef]

59. Barbosa, C.; Peixeiro, I.; Romão, L. Gene expression regulation by upstream open reading frames and human disease. PLoS Genet. 2013, 9, e1003529. [CrossRef] 